\title{
Genetic and Clinical Profiles of Disseminated Bacillus Calmette-Guérin Disease and Chronic Granulomatous Disease in China
}

OPEN ACCESS

Edited by:

Guzide Aksu,

Ege University, Turkey

Reviewed by:

Ruben Martinez-Barricarte,

Rockefeller University, United States

Saul Oswaldo Lugo Reyes,

National Institute of Pediatrics, Mexico

${ }^{*}$ Correspondence:

Shuihua Lu

lushuihua66@126.com

Wen-Hong Zhang

zhangwenhong@fudan.edu.cn

†These authors have contributed equally to this work

Specialty section:

This article was submitted to Primary Immunodeficiencies,

a section of the journal

Frontiers in Immunology

Received: 16 October 2018 Accepted: 11 January 2019 Published: 29 January 2019

Citation:

Li T, Zhou X, Ling Y, Jiang N, Ai J, Wu J, Chen J, Chen L, Qian X, Liu X, $X i X$, Xia L, Fan X, Lu S and Zhang W-H (2019) Genetic and

Clinical Profiles of Disseminated Bacillus Calmette-Guérin Disease and Chronic Granulomatous Disease in

China. Front. Immunol. 10:73. doi: 10.3389/fimmu.2019.00073
Tao $\mathrm{Li}^{1+}$, Xian Zhou ${ }^{1+}$, Yun Ling ${ }^{2+}$, Ning Jiang ${ }^{3}$, Jingwen $\mathrm{Ai}^{1}$, Jing $\mathrm{Wu}^{1}$, Jiazhen Chen ${ }^{1}$, Li Chen ${ }^{4}$, Xiaowen Qian ${ }^{5}$, Xuhui Liu ${ }^{2}$, Xiuhong $\mathrm{Xi}^{2}$, Lu Xia ${ }^{2}$, Xiaoyong Fan ${ }^{2}$, Shuihua $\mathrm{Lu}^{2 *}$ and Wen-Hong Zhang ${ }^{1 *}$

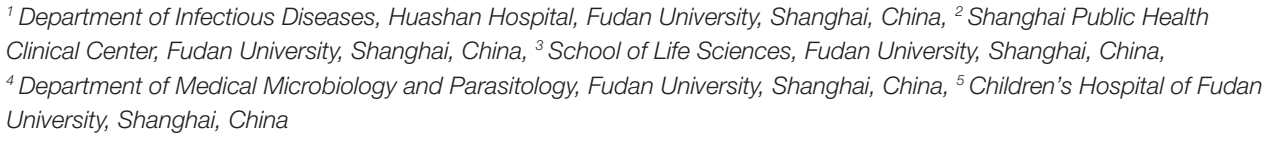
Clinical Center, Fudan University, Shanghai, China, ${ }^{3}$ School of Life Sciences, Fudan University, Shanghai, China, ${ }^{4}$ Department of Medical Microbiology and Parasitology, Fudan University, Shanghai, China, ${ }^{5}$ Children's Hospital of Fudan University, Shanghai, China

Background: Disseminated Bacillus Calmette-Guérin disease (D-BCG) in children with chronic granulomatous disease (CGD) can be fatal, while its clinical characteristics remain unclear because both diseases are extremely rare. The patients with CGD receive BCG vaccination, because BCG vaccination is usually performed within $24 \mathrm{~h}$ after delivery in China.

Methods: We prospectively followed-up Chinese patients with CGD who developed D-BCG to characterize their clinical and genetic characteristics. The diagnoses were based on the patients' clinical, genetic, and microbiological characteristics.

Results: Between September 2009 and September 2016, we identified 23 patients with CGD who developed D-BCG. Their overall 10-year survival rate was 34\%. We created a simple dissemination score to evaluate the number of infected organ systems and the survival probabilities after 8 years were 62 and $17 \%$ among patients with simple dissemination scores of $\leq 3$ and $>3$, respectively $(p=0.0424)$. Survival was not significantly associated with the CGD stimulation index or interferon- $\gamma$ treatment. Eight patients underwent umbilical cord blood transplantation and 5 of them were successfully treated. The genetic analyses found mutations in CYBB (19 patients), CYBA (1 patient), NCF1 (1 patient), and NCF2 (1 patient). We identified 6 novel highly likely pathogenic mutations, including 4 mutations in CYBB and 2 mutations in NCF1.

Conclusions: D-BCG is a deadly complication of CGD. The extent of BCG spreading is strongly associated with clinical outcomes, and hematopoietic stem cell transplantation may be a therapeutic option for this condition.

Keywords: Bacillus Calmette-Guérin, disseminated BCG disease, BCGosis, vaccination, chronic granulomatous disease, complications 


\section{INTRODUCTION}

Bacille Calmette-Guerin (BCG), an attenuated strain of Mycobacterium bovis, was originally isolated from a cow with tuberculosis. The BCG vaccine was first used to immunize humans in 1921 (1). With protective effect against lifethreatening tuberculosis(TB) such as tuberculosis meningitis and disseminated TB in children, BCG vaccination is recommended in countries with a high TB burden (2). It is one of the most widely used of all current vaccines and over 150 countries have universal BCG vaccination program (3). Although more than 14 substrains of BCG have been used as BCG vaccine strains in different parts of the world differ in terms of their genetic and phenotypic properties, commonly administered BCG vaccine strains induce comparable protective immunity against TB (1).

Disseminated Bacillus Calmette-Guérin (D-BCG) disease is the most fatal adverse event after BCG vaccination, and is associated with a mortality rate of $60-80 \%$ (4-6). Early studies have indicated that acquired or inherited immunodeficiency can predispose the patient to infection with an attenuated strain of M. bovis BCG (7). Among them, chronic granulomatous disease (CGD) is one of the representative (8). Patients with CGD suffer from a variety of recurrent bacterial and fungal infections (9). It is caused by an inherited defect in the nicotinamide adenine dinucleotide phosphate (NADPH) oxidase enzyme complex that consists of two membrane-spanning subunits, gp91phox and $\mathrm{p} 22^{\text {phox }}$, as well as three cytosolic components $\mathrm{p} 47^{\text {phox }}, \mathrm{p} 67^{\text {phox }}$, and $\mathrm{p} 40^{\text {phox }}(10)$. Mutations within the X-linked gp91 phox gene $(C Y B B)$ cause the X-linked form of CGD, while the autosomal recessive forms of CGD are due to mutations in in CYBA, NCF1, NCF2, or NCF4 which encode for $\mathrm{p} 22^{\text {phox }}, \mathrm{p} 47^{\text {phox }}, \mathrm{p} 67^{\text {phox }}$, and p40 phox, respectively (10).

BCG vaccination is contraindicated for persons with congenital cell-mediated or severe combined immunodeficiency, immunodeficiency syndromes (e.g., HIV/AIDS, known or suspected congenital immunodeficiency, leukemia, lymphoma, or other malignant disease) (2). Because patients with CGD have impaired reactive oxygen species [ROS]-producing phagocyte NADPH oxidase, which may weaken their antimycobacterial defense (8), CGD is one of the contraindications of BCG vaccination. However, as BCG is usually vaccinated very early in infancy, there is not enough time to screen for CGD and other vaccination contraindications. Many reports have described minor BCG complications, such as regional lymphadenitis, in CGD cases (11-16), D-BCG associated with CGD is extremely rare $(14,17)$, as the incidences of D-BCG and CGD are $\sim 2$ cases per 1 million vaccinations (18) and 5 cases per 1 million live births (19), respectively. This manuscript describes the genetic and clinical characteristics of 23 Chinese patients with D-BCG associated with CGD.

\footnotetext{
Abbreviations: BCG, Bacille Calmette-Guerin; CGD, chronic granulomatous disease; D-BCG, Disseminated Bacillus Calmette-Guérin disease; DHR, dihydrorhodamine 123; HSCT, hematopoietic stem cell transplantation; IFN, interferon; NADPH, nicotinamide adenine dinucleotide phosphate; SI, stimulation index; TB, tuberculosis; UCBT, umbilical cord blood transplantation
}

\section{MATERIALS AND METHODS}

\section{Case Definition}

CGD was diagnosed based on the patient's clinical presentation and confirmed using either the dihydrorhodamine 123 (DHR) oxidation assay or genetic analysis. DHR assay is tested using FACScam(Becton Dickinson, CA, USA) with methods established by $\mathrm{Yu}$ et al. (20). We detected $C Y B B$ mutation by PCR using synthetic oligonucleotide primers designed to amplify the $C Y B B$ gene. For patients with $C Y B B$ mutation negative, we performed whole exon sequencing. D-BCG was classified according to the criteria in Table 1. A simple dissemination site-based score (1 point per involved organ system) was used to evaluate the degree of dissemination to the lungs, bones, liver, spleen, kidney, heart or pericardium, gastrointestinal tract, peritoneum, nose, ears, skin, and soft tissues. The scoring was performed by attending physicians based on the results of the clinical examination, imaging, and laboratory testing.

\section{Data Collection}

We conducted a prospective observational study to follow up patients who had clinical symptoms of D-BCG and were hospitalized at the Shanghai Public Health Clinical Center of Fudan University from September 1, 2009, to September 1, 2016. All patients and/or their guardians provided written informed consent to be followed-up. This study's observational protocol was approved by the ethics committee of the hospital. The

TABLE 1 | The diagnostic criteria and classifications for Bacillus Calmette-Guérin (BCG) disease.

\section{DIAGNOSTIC CRITERIA}

1. A history of $B C G$ vaccination: vaccination record showing $B C G$ vaccination.

2. Evidence of dissemination: evidence of BCG infection at the presentation that involved $\geq 1$ anatomical site in addition to that of the vaccination site and its regional lymph nodes.

3. Pathology/etiology: clinical specimen that was positive for Mycobacterium tuberculosis complex based on culturing, acid-fast staining, and histological detection of caseating granuloma.

4. BCG identification: real-time PCR (careTB PCR ASSAY kit, Qiagen) was performed to identify the $M$. tuberculosis complex according to the manufacturer's instructions. Positive specimens were subsequently testing using a BCG assay based upon genomic deletions at RD1, 9, and 10, which was established by Parsons et al. (21).

\section{DIAGNOSTIC CLASSIFICATIONS}

\section{Definite (all of the following criteria)}

History of BCG vaccination

Evidence of dissemination

Evidence regarding the pathology/etiology

BCG identification

Highly probable (all of the following criteria)

History of BCG vaccination

Evidence of dissemination

Evidence regarding the pathology/etiology

\section{Probable (all of the following criteria)}

History of BCG vaccination

Evidence of dissemination 
TABLE 2 | Patient characteristics.

\begin{tabular}{|c|c|}
\hline & $N$ \\
\hline \multicolumn{2}{|c|}{ DISTRIBUTION OF GENETIC MUTATIONS } \\
\hline CYBB & 19 \\
\hline CYBA & 1 \\
\hline NCF1 & 1 \\
\hline NCF2 & 1 \\
\hline \multicolumn{2}{|c|}{ DISSEMINATED BCG DISEASE DIAGNOSIS } \\
\hline Definite & 6 \\
\hline Highly probable & 9 \\
\hline Probable & 8 \\
\hline \multicolumn{2}{|l|}{ FAMILY HISTORY } \\
\hline Early death of male sibling & 4 \\
\hline Consanguine marriage & 1 \\
\hline Recurrent spontaneous abortion & 1 \\
\hline \multicolumn{2}{|l|}{ FOLLOW-UP } \\
\hline Alive & 11 \\
\hline Deceased & 10 \\
\hline Lost to follow-up & 2 \\
\hline
\end{tabular}

BCG, Bacillus Calmette-Guérin; CYBB, the beta chain of cytochrome b; CYBA, the alpha chain of cytochrome b; NCF1, neutrophil cytosolic factor 1; NCF2, neutrophil cytosolic factor 2 .

patients were diagnosed and categorized based on the criteria that are listed in Table 1, and their clinical, radiological, pathological, and microbiological characteristics.

\section{Statistical Analysis}

All statistical analyses were performed using GraphPad Prism (version 6.0) and IBM SPSS software (version 22.0). Categorical and continuous variables were compared using Fisher's exact test and the Mann-Whitney $U$-test, respectively. Kaplan-Meier survival curves were compared between the groups using the log-rank test. All tests were two-sided, and differences were considered statistically significant at $p<0.05$.

\section{RESULTS}

Between September 2009 and September 2016, 78 patients were diagnosed with D-BCG at our center. Among them, 23 patients were diagnosed with CGD (Table 2). The diagnosis of CGD was based on DHR testing in 1 patient, genetic analysis in 6 patients, and a combination of DHR testing and genetic analysis in 16 patients. The diagnoses of D-BCG in CGD patients were definite in 6 patients, highly probable in 9 patients, and probable in 8 patients. All 23 patients were male, and their median age at referral to our hospital was 12.2 months (mean: 25.7 months, range: $2.9-123.7$ months). The children were from 23 different families that resided in 10 Chinese provinces (mostly in the southeast region). All patients had undergone BCG vaccination with strain $\mathrm{D}_{2} \mathrm{~PB} 302$ at the left deltoid region within $24 \mathrm{~h}$ after birth, based on the national vaccination policy and protocol.

The median age at the onset of BCG disease was 3.0 months (mean: 7.6 months, range: $0.3-58.5$ months) (Figure 1A). Nineteen of the 23 children $(82.6 \%)$ had symptoms of BCG disease before the age of 1 year. The median age at the diagnosis of D-BCG was 12.4 months (mean: 24.7 months, range: $2.9-123.1$ months) (Figure 1B). The median lag between the onset and diagnosis of BCG disease was 5.4 months (mean: 17.2 months, range: $0.6-121.1$ months). Seventeen of the 23 children (73.9\%) developed symptoms of BCG disease as the initial symptom of CGD. The median age at the diagnosis of CGD was 12.6 months (mean: 23.9 months, range: 1.3-121.1 months), and 13 of the 23 patients had been diagnosed with D-BCG before developing CGD.

The local adverse reactions to the BCG vaccine included left axillary lymph node enlargement $(n=15,65 \%)$ and an abscess at the vaccination site $(n=4,17 \%)$. The initial symptoms of D-BCG were fever $(n=17,74 \%)$, multiple lymph node enlargement $(n=$ $7,30 \%)$, cough $(n=5,22 \%)$, ascites $(n=1,4 \%)$, and diarrhea $(n=1,4 \%)$ (Figure 1C). As the infection deteriorated, various organs developed signs of BCG dissemination (Figure 1D). Most patients $(n=22,96 \%)$ had pulmonary involvement, 14 patients (61\%) had multiple systematic lymph node enlargement, and abdominal involvement was common (ascites: 6 patients, liver involvement: 5 patients, gastrointestinal tract involvement: 2 patients, splenomegaly: 1 patient, and hydronephrosis: 1 patient). Five patients $(22 \%)$ had bone lesions, 3 patients had BCG dissemination to the skin or soft tissues beyond the vaccination site, and 2 patients had BCG dissemination to the pericardium. We also observed dissemination to the central nervous system, nose, ears, and penis (1 patient each). The average simple dissemination score was 2.8 affected organ systems (range: 1-6 organ systems).

At the last follow-up (April 21, 2018), 10 patients (44\%) had died from complications of D-BCG at a median age of 21.3 months (mean: 35.2 months, range: 6.2-102.0 months), 11 patients (48\%) were alive, and 2 patients (9\%) had been lost to follow-up. The overall 10-year survival rate was $34 \%$ (Figure S1A). The survival probabilities after 8 years were 62\% among patients with a dissemination score of $\leq 3$ and $17 \%$ among patients with a dissemination score of $>3(p=0.0424)$ (Figure 2A).

Among the 17 patients that underwent DHR testing, the median stimulation index (SI) was 2.79 (mean: 5.31, range: 1.518.4). There was no significant difference in the SI values when we compared deceased and surviving patients (Mann-Whitney test, $p=0.9336)$. The survival probabilities after 8 years were $44 \%$ for patients with an SI of $\leq 2.8$ and $54 \%$ for patients with an SI of $>2.8(p=0.5946)$ (Figure 2B).

In addition to the BCG infection, 14 patients $(61 \%)$ had other infections that were caused by a virus, fungus, or bacterium. Six patients had $\geq 2$ infections, and 7 patients had disseminated infection caused by chronic active EpsteinBarr virus infection (2 patients), blood culture-confirmed bacterial infections (4 patients), and autopsy-confirmed tuberculosis infection (1 patient). The most frequently isolated organisms were Klebsiella pneumonia and Aspergillus spp., and the lungs were the most frequently involved organs.

After the diagnosis, all patients received anti-BCG treatment, which was generally based on a regimen of isoniazid, rifampin, and ethambutol. Some patients received alternative treatment because of isoniazid resistance ( 1 patient), adverse reactions ( 5 


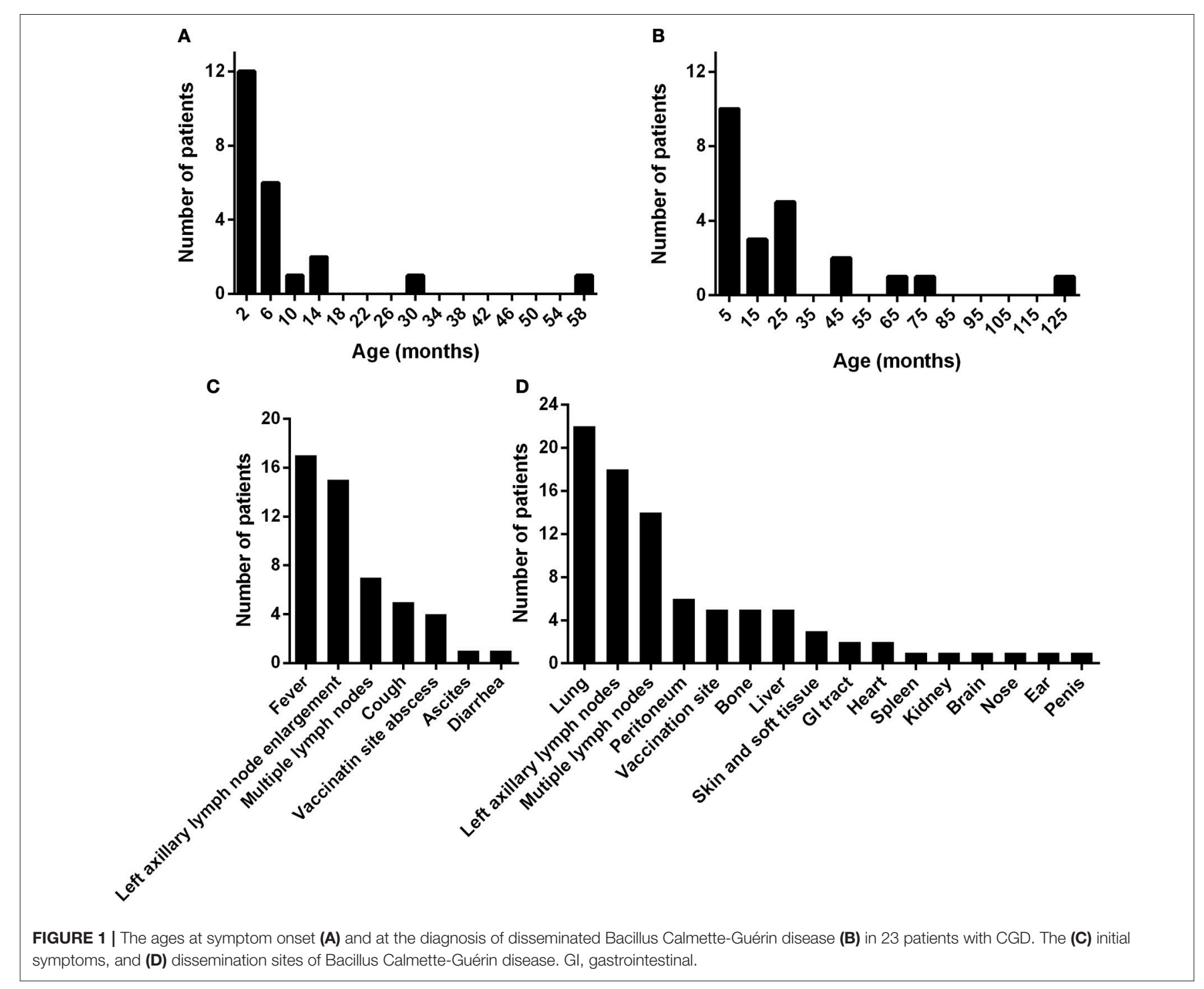

patients), or clinical experience. As the subtle changes in the antiBCG regimen were too complicated to analyze throughout the long-term treatment, we have listed the regimens in Table 3.

Interferon (IFN) $-\gamma$ was added to the treatment protocol for 11 patients. The use of IFN- $\gamma$ was not associated with the dissemination score (Fisher's exact test, $p=1.0000$ ), and the survival probabilities after 8 years were not significantly different between patients who did and did not receive IFN- $\gamma$ treatment (36 vs. $73 \%, p=0.2599$ ) (Figure $2 C$ ). Eight patients underwent umbilical cord blood transplantation (UCBT), with a success rate of $63 \%$ ( 5 cases). 3 of 5 children who underwent successful UCBT have stopped the anti-BCG treatment. One child died at 4 months after failed UCBT. The other 2 child failed UCBT is continuing the anti-BCG treatment and waiting for the second one. The survival probabilities after 8 years were $88 \%$ among patients with UCBT and $38 \%$ among patients without UCBT $(p=0.0790)$ (Figure 2D).

Nineteen patients $(82.6 \%)$ had X-linked recessive mutations in $C Y B B$ gene. One child's mother had a history of recurrent spontaneous abortion and 4 children had deceased brothers who died before the age of 1 year. Additionally, three children were identified with compound heterozygous or hemizygous mutations in other autosomal genes, including CYBA (1 patient), NCF1 (1 patient), and NCF2 (1 patient). A homozygous nonsense mutation (NM_000433.3: c.304C > T) was found in NCF2 of one male, whose parents were consanguineous and carried the heterozygous mutation in this locus. Furthermore, we identified 6 novel highly likely pathogenic mutations, including 4 mutations in $C Y B B$ and 2 mutations in NCF1 (Figure 3 and Table 3 ).

\section{DISCUSSION}

As both diseases have very low incidence rates, the clinical characteristics of D-BCG with CGD remains unclear. The present study evaluated 23 Chinese cases of D-BCG with CGD, which is, to the best of our knowledge, the largest reported cohort of these patients. The development of antifungal and antibiotic treatments has greatly decreased the mortality rate in conventionally treated CGD cases, and most patients can survive until their thirties $(19,27)$. However, the prognosis of patients 
A

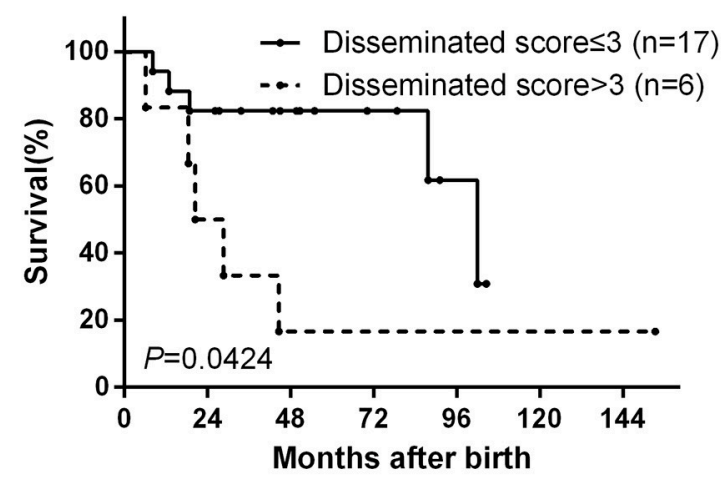

C

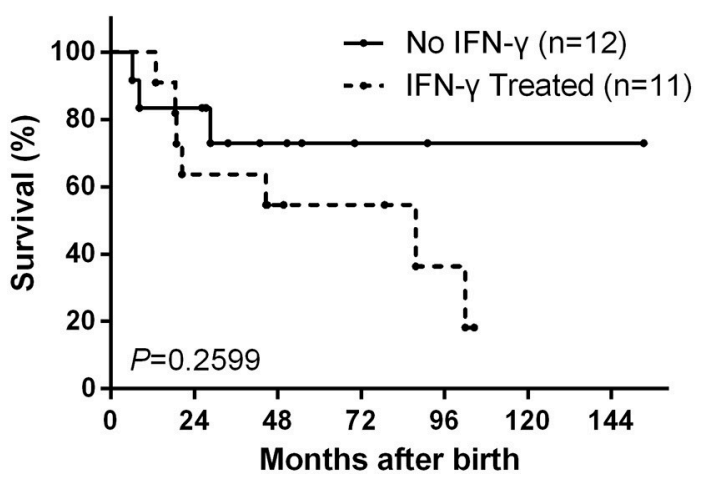

B

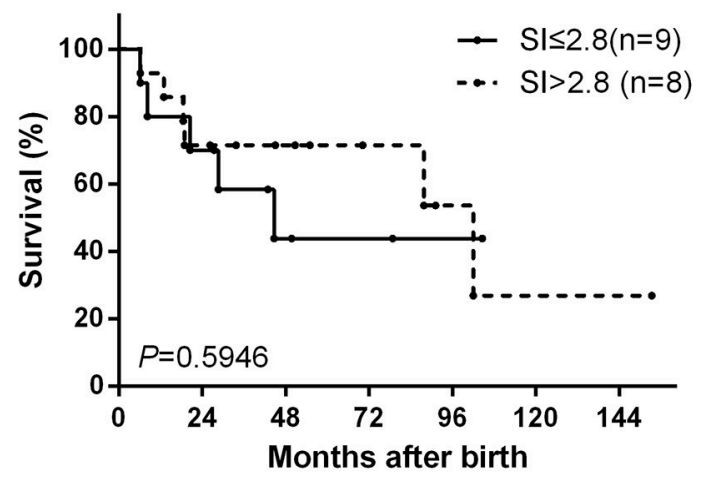

D

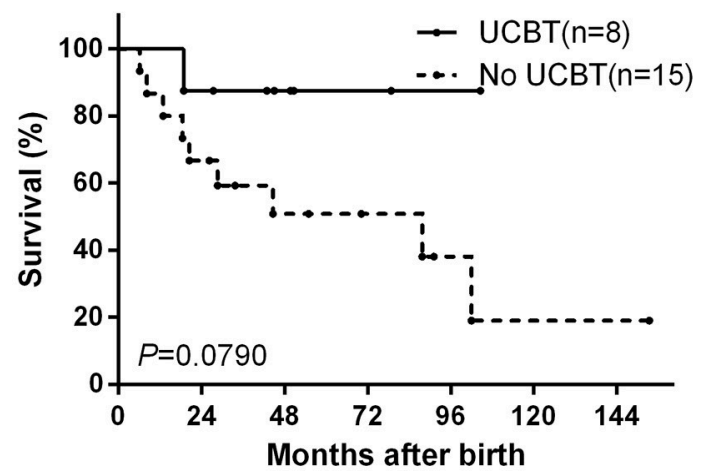

FIGURE 2 | Kaplan-Meier survival curves from the date ot birth. The curves are shown for (A) according to dissemination score, (B) according to the dihydrorhodamine assay stimulation index (SI), (C) according to interferon (IFN)- $\gamma$ treatment status, and (D) according to umbilical cord blood transplantation (UCBT) status.

with D-BCG and CGD remains poor. The 10-year survival rate in our cohort was $34 \%$, which is consistent with the findings of previous studies $(4,18)$. Compared to D-BCG patients with unknown genetic defects, D-BCG patients with CGD required longer anti-BCG treatment (Figure S1B).

In the present study, 5 of 8 patients were successfully treated using UCBT, and 3 of 5 successful UCBT patients have stopped anti-BCG treatment, which indicates that UCBT may be a curative treatment for patients with CGD. Furthermore, compared to conventionally treated CGD, a previous study revealed that hematopoietic stem cell transplantation (HSCT) was associated with lower rates of infection and hospitalization (28). Although our small sample size limited the power of this analysis, we noticed an improved survival rate in this subgroup, and suggest considering early HSCT for patients with D-BCG and CGD, given the deadly effects of BCG dissemination. Unfortunately, the precise timing and conditioning intensity remain unclear for using HSCT to treat primary immunodeficiency (29), and this problem would be further aggravated among patients with BCG infection, given the lack of useful data.

Unlike relatively mild BCG complications that are usually limited to the regional lymph nodes $(14,30)$, our patients with
D-BCG exhibited characteristic BCG dissemination to distant organs. Thus, we created a simple dissemination score to evaluate the number of infected organ systems, and found that it was both easy to measure and may help predict the prognosis in cases of D-BCG with CGD, which is quite bad for patients with score more than 3. In the present study, the BCG dissemination most commonly involved the lungs and systemic lymph nodes, with 22 of 23 cases exhibiting lung involvement and 13 of 23 cases exhibiting concurrent lung and systemic lymph node involvement.

More than 700 different mutations responsible for CGD have been identified (31), and we found 6 new mutations, 4 in $C Y B B$ and 2 in NCF1. Although we did not perform functional experiment, the clinical presentation, compromised granulocyte function with evidence of DHR assay and non-synonymous mutations in CGD-related genes were convicing evidence for causative mutations. However, the correlation between the genotype and the clinical presention, especially the occurrence of D-BCG in CGD patients is not clear. For BCG-vaccinated CGD patients, $8-56 \%$ of them had BCG lymphadenitis (11, $13,15,16,27), 0-10 \%$ had D-BCG $(11-13)$. The present study did not reveal a significant association between D-BCG and the DHR assay's SI value (residual NADPH oxidase function). 
TABLE 3 | The cohort's clinical and genetic characteristics.

\begin{tabular}{|c|c|c|c|c|c|c|c|c|c|}
\hline $\begin{array}{l}\text { Patient } \\
\text { no. }\end{array}$ & Province & CGD diagnosis & Mutation & $\begin{array}{l}\text { Amino acid } \\
\text { change }\end{array}$ & SI & $\begin{array}{l}\text { BCG } \\
\text { diagnosis }\end{array}$ & Other infections & $\begin{array}{l}\text { Anti-BCG } \\
\text { treatment }\end{array}$ & Follow-up \\
\hline 1 & Zhejiang & Genetic & $C Y B A^{\wedge}$ & & & Probable & Epstein-Barr virus & HELfx & $\begin{array}{l}\text { Alive (stopped } \\
\text { anti-BCG treatment) }\end{array}$ \\
\hline 2 & Hubei & DHR/genetic & $\begin{array}{l}\text { NCF2 c.304C>T } \\
\text { (22) }\end{array}$ & p.(Arg102*) & 2.13 & Definite & - & HRZE & Deceased \\
\hline 3 & Henan & DHR/genetic & $\begin{array}{l}C Y B B \\
\text { c. } 466 G>A(22)\end{array}$ & p.(Ala156Thr) & 18 & Definite & $\begin{array}{l}\text { Pseudomonas } \\
\text { putida, Klebsiella } \\
\text { pneumoniae }\end{array}$ & EAmkLzd & Deceased \\
\hline 4 & Henan & Genetic & $\begin{array}{l}\text { CYBB } \\
\text { c.1514T>C (23) }\end{array}$ & p.(Leu505Pro) & & Definite & $\begin{array}{l}\text { Aspergillus spp., } \\
\text { Epstein-Barr virus }\end{array}$ & HRZE & Deceased \\
\hline 5 & Zhejiang & DHR/genetic & $\begin{array}{l}\text { CYBB } \\
{ }^{{ }_{C} .277 C>T}\end{array}$ & p. $\left(\mathrm{G} \ln 93^{\star}\right)$ & 2.2 & Definite & Mumps virus & HRE & Deceased \\
\hline 6 & Jiangsu & DHR/genetic & $\begin{array}{l}\text { CYBB } \\
{ }^{\#} \text { C.337_338del }\end{array}$ & $\begin{array}{l}\text { del exon 5? } \\
\text { p.(Ala113fs)? }\end{array}$ & 2.43 & Definite & Fungal & HRE & $\begin{array}{l}\text { Alive (stopped } \\
\text { anti-BCG treatment) }\end{array}$ \\
\hline 9 & Zhejiang & DHR/genetic & $\begin{array}{l}\text { CYBB }{ }^{\#} \text { C.1151 } \\
+1 \_1151+2 \text { del }\end{array}$ & del exon 9? & 4.54 & $\begin{array}{l}\text { Highly } \\
\text { probable }\end{array}$ & - & HRE & Deceased \\
\hline 10 & Fujian & DHR/genetic & $\begin{array}{l}\text { CYBB } \\
\text { c. } 1082 G>T(24)\end{array}$ & p.(Trp361Leu) & 3.38 & $\begin{array}{l}\text { Highly } \\
\text { probable }\end{array}$ & $\begin{array}{l}\text { Aspergillus } \\
\text { terreus, } \\
\text { Cellulomonas spp. }\end{array}$ & ClrEMfx & Deceased \\
\hline 11 & Shanghai & DHR/genetic & $C Y B B^{\wedge}$ & & 2.79 & $\begin{array}{l}\text { Highly } \\
\text { probable }\end{array}$ & & HRE & $\begin{array}{l}\text { Alive (stopped } \\
\text { anti-BCG treatment) }\end{array}$ \\
\hline 12 & Anhui & DHR/genetic & $C Y B B^{\wedge}$ & & 18.4 & $\begin{array}{l}\text { Highly } \\
\text { probable }\end{array}$ & $\begin{array}{l}\text { Staphylococcus } \\
\text { aureus, G+ cocci, } \\
\text { G- cocci }\end{array}$ & HRE & Unkown \\
\hline 13 & Anhui & DHR/genetic & $\begin{array}{l}\text { CYBB } \\
\text { c. } 1499 A>G(25)\end{array}$ & p.(Asp500Gly) & 8.84 & $\begin{array}{l}\text { Highly } \\
\text { probable }\end{array}$ & $\begin{array}{l}\text { Enterococcus } \\
\text { faecium, Klebsiella } \\
\text { pneumoniae, } \\
\text { Escherichia coli }\end{array}$ & HELfx & Deceased \\
\hline 16 & Jilin & DHR/genetic & $\begin{array}{l}\text { CYBB c.1095del } \\
\text { (26) }\end{array}$ & p.(Phe366fs) & 2.3 & Probable & - & $\mathrm{HR}$ & $\begin{array}{l}\text { Alive (continuing } \\
\text { anti-BCG treatment) }\end{array}$ \\
\hline 17 & Jiangsu & DHR/genetic & $C Y B B^{\wedge}$ & & 1.9 & $\begin{array}{l}\text { Highly } \\
\text { probable }\end{array}$ & - & $H R$ & $\begin{array}{l}\text { Alive (continuing } \\
\text { anti-BCG treatment) }\end{array}$ \\
\hline 18 & Jiangxi & DHR/genetic & $C Y B B^{\wedge}$ & & 1.5 & Probable & $\mathrm{G}+$ cocci & HERft & $\begin{array}{l}\text { Alive (continuing } \\
\text { anti-BCG treatment) }\end{array}$ \\
\hline 19 & Hunan & DHR & $\mathrm{N} / \mathrm{A}$ & & 2.31 & $\begin{array}{l}\text { Highly } \\
\text { probable }\end{array}$ & Candida spp. & ELzdAmkPas & Deceased \\
\hline 20 & Hunan & DHR/genetic & $\begin{array}{l}\text { CYBB } \\
\text { c. } 1082 G>T(24)\end{array}$ & p.(Trp361Leu) & 2.85 & Definite & $\begin{array}{l}\text { Mycobacterium } \\
\text { chelonae subsp. } \\
\text { M. abscessus; } M \text {. } \\
\text { intracellulare; } M \text {. } \\
\text { tuberculosis }\end{array}$ & $\mathrm{HR}$ & Deceased \\
\hline 21 & Zhejiang & Genetic & $C Y B B^{\wedge}$ & & & Probable & - & $\mathrm{HR}$ & Unknown \\
\hline 22 & Jiangsu & Genetic & $\begin{array}{l}\text { CYBB } \\
\text { C. } 1085 C>T(26)\end{array}$ & p.(Thr362lle) & & Probable & $\begin{array}{l}\text { Staphylococcus } \\
\text { epidermidis }\end{array}$ & HRE & $\begin{array}{l}\text { Alive (continuing } \\
\text { anti-BCG treatment) }\end{array}$ \\
\hline 23 & Jiangsu & DHR/genetic & $\begin{array}{l}\text { CYBB } \\
\text { c.1165G>A (26) }\end{array}$ & p.(Gly389Arg) & 4.15 & Probable & - & HRE & $\begin{array}{l}\text { Alive (stopped } \\
\text { anti-BCG treatment) }\end{array}$ \\
\hline
\end{tabular}

${ }^{\wedge}$ The mutation was noted on the clinical report without site specifications. "Novel mutation site. ? Amino acid change predicted at splice sites. "Designates a translation termination codon. DHR, dihydrorhodamine; BCG, Bacillus Calmette-Guérin; CYBB, the beta chain of cytochrome b; CYBA, the alpha chain of cytochrome b; NCF1, neutrophil cytosolic factor 1; NCF2, neutrophil cytosolic factor 2; H, isoniazid; R, rifampicin; Z, pyrazinamide; E, ethambutol; Lfx, levofloxacin; Amk, amikacin; Lzd, linezolid; Pas, para-aminosalicylic acid; Mfx, moxifloxacin; Pto, protionamide; Rft, rifapentine. 


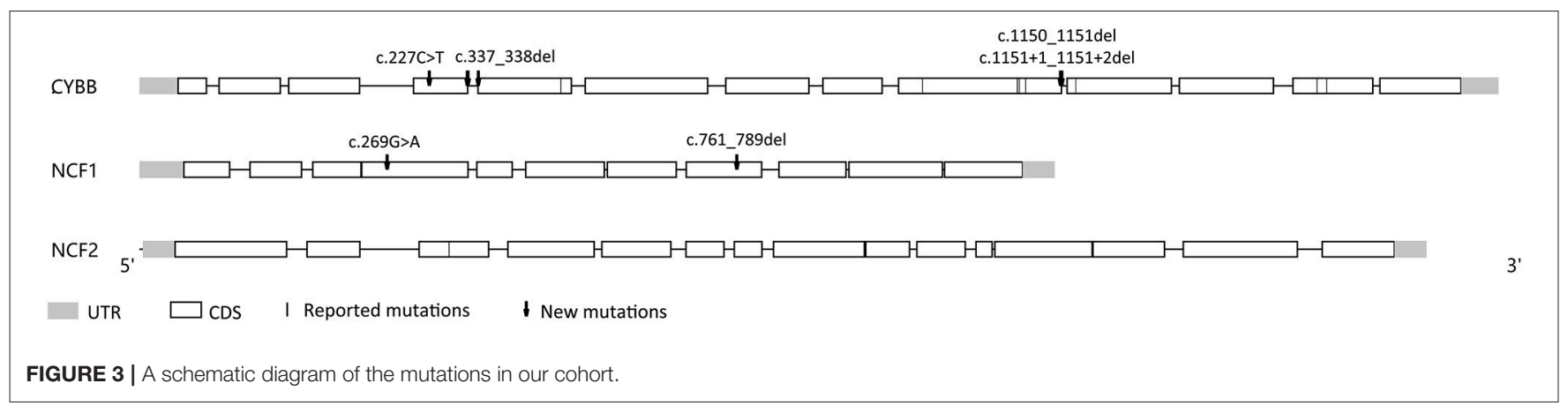

This result is different from the findings of two previous studies $(15,32)$, but is consistent with the findings of Köker et al. in Turkey (15). Similar to China, Turkey has a national policy of BCG vaccination, and Köker et al. concluded that the residual NADPH oxidase activity of neutrophils was associated with later and less severe clinical presentation, although it did not affect the occurrence of BCG. Early studies have indicated that $C Y B B$ mutations (33) can cause a selectively impaired respiratory burst in macrophages and are associated with mendelian susceptibility to mycobacterial disease. Thus, the residual NADPH oxidase function of macrophages could be a useful predictor of prognosis among patients with both BCG and CGD.

The efficacy of IFN- $\gamma$ for treating CGD remains controversial (34-37). The most cited study supporting the use of IFN$\gamma$ therapy was a randomized double-blind placebo-controlled trial of 128 patients with CGD, and revealed that IFN- $\gamma$ substantially reduced the frequency of serious infections (34). However, a prospective multicenter study in Italy (37) found that long-term use of IFN- $\gamma$ did not change the rate of infections per patient-year. In those studies, the IFN- $\gamma$ was administered prophylactically and the primary endpoints were serious infections, while we evaluated treatment during the active infection period and survival outcomes. Therefore, additional studies are needed to provide better evidence regarding the efficacy of IFN- $\gamma$ treatment for CGD.

Our study is limited by its observational nature and the small sample size, which limited the power of our statistics analyses. Furthermore, the sample size is too small to perform multivariate survival analysis. However, both D-BCG and CGD are extremely rare diseases, and the 23 cases in our cohort provide valuable information regarding the genetic and clinical characteristics of patients with both D-BCG and CGD.

\section{CONCLUSION}

This study of 23 Chinese patients with D-BCG and CGD confirmed that D-BCG is a severe complication of CGD, and CGD patients is a subgroup of D-BCG patients with relatively poor prognosis. The extent of BCG spreading was strongly associated with clinical outcomes, although these outcomes were not associated with the residual NADPH oxidase function of neutrophils. Furthermore, IFN- $\gamma$ therapy during active BCG infection was not associated with an improved survival rate. Based on our findings, we suggest that all patients with this fatal disease should be considered for early HSCT.

\section{AUTHOR CONTRIBUTIONS}

TL, XZ, YL, SL, and W-HZ: conception or design of the work; TL, XZ, XQ, LX, XL, and XX: data collection and patient care; TL, XZ, NJ, JA, JW, JC, and XF: data analysis and interpretation; TL and XZ: drafting the article. YL, JW, LC, and W-HZ: critical revision of the article; TL, XZ, YL, NJ, JA, JW, JC, LC, XQ, XL, XX, LX, $\mathrm{XF}$, SL, and W-HZ: Final approval of the version to be published.

\section{FUNDING}

The present study was partly supported by Shanghai Public Health Clinical Center (SPHCC-KY-GW-2017-08), the Key Technologies Research and Development Program for Infectious Diseases of China (2017ZX10202301-003, 2017ZX10301301-004) and National Natural Science Foundation of China 81700014, 81373064).

\section{SUPPLEMENTARY MATERIAL}

The Supplementary Material for this article can be found online at: https://www.frontiersin.org/articles/10.3389/fimmu. 2019.00073/full\#supplementary-material

\section{REFERENCES}

1. World Health Organization and WHO Expert Committee on Biological Standardization. WHO Expert Committee on Biological Standardization: SixtySecond Report. World Health Organization (2013).

2. World Health Organization. BCG vaccines: WHO position paper - February 2018. Wkly Epidemiol Rec. (2018) 93:73-96. doi: 10.1016/j.vaccine.2018. 03.009

3. Zwerling A, Behr MA, Verma A, Brewer TF, Menzies D, Pai M. The BCG World Atlas: a database of global BCG vaccination policies and 
practices. PLoS Med. (2011) 8:e1001012. doi: 10.1371/journal.pmed.10 01012

4. Lotte A, Wasz-Hockert O, Poisson N, Engbaek H, Landmann H, Quast U, et al. Second IUATLD study on complications induced by intradermal BCGvaccination. Bull Int Union Against Tuberculosis Lung Dis. (1988) 63:47-59.

5. Sadeghi-Shanbestari M, Ansarin K, Maljaei SH, Rafeey M, Pezeshki Z. Immunologic aspects of patients with disseminated bacille CalmetteGuerin disease in north-west of Iran. Ital J Pediatr. (2009) 35:42 doi: 10.1186/1824-7288-35-42

6. Paiman SA, Siadati A, Mamishi S, Tabatabaie P, Khotaee G. Disseminated Mycobacterium bovis infection after BCG vaccination. Iran J Allergy Asthma Immunol. (2006) 5:133-7. Available online at: http:// ijaai.tums.ac.ir/index.php/ijaai/article/view/146

7. Boisson-Dupuis S, Bustamante J, El-Baghdadi J, Camcioglu Y, Parvaneh $\mathrm{N}$, El Azbaoui $\mathrm{S}$, et al. Inherited and acquired immunodeficiencies underlying tuberculosis in childhood. Immunol Rev. (2015) 264:103-20. doi: $10.1111 /$ imr.12272

8. Deffert C, Cachat J, Krause K. Phagocyte NADPH oxidase, chronic granulomatous disease and mycobacterial infections. Cell Microbiol. (2014) 16:1168-78. doi: $10.1111 / \mathrm{cmi} .12322$

9. Roos D. Chronic granulomatous disease. Brit Med Bull. (2016) 118:50-63. doi: 10.1093/bmb/ldw009

10. Goldblatt D. Recent advances in chronic granulomatous disease. I Infect. (2014) 69:S32-35. doi: 10.1016/j.jinf.2014.07.013

11. Baba LA, Ailal F, El Hafidi N, Hubeau M, Jabot-Hanin F, Benajiba N, et al. Chronic granulomatous disease in morocco: genetic, immunological, and clinical features of 12 patients from 10 Kindreds. J Clin Immunol. (2014) 34:452-8. doi: 10.1007/s10875-014-9997-3

12. Xu H, Tian W, Li S, Zhang L, Liu W, Zhao Y, et al. Clinical and molecular features of 38 children with chronic granulomatous disease in Mainland China. J Clin Immunol. (2014) 34:633-41. doi: 10.1007/s10875-0140061-0

13. Lee PPW, Chan K, Jiang L, Chen T, Li C, Lee T, et al. Susceptibility to mycobacterial infections in children with $\mathrm{x}$-linked chronic granulomatous disease. Pediatric Infect Dis J. (2008) 27:224-30. doi: 10.1097/INF.0b013e31815b494c

14. Conti F, Lugo-Reyes SO, Blancas GL, He J, Aksu G, Borges DOEJ, et al. Mycobacterial disease in patients with chronic granulomatous disease: a retrospective analysis of 71 cases. J Allergy Clin Immunol. (2016) 138:241-8. doi: 10.1016/j.jaci.2015.11.041

15. Köker MY, Camcioglu Y, van Leeuwen K, Kiliç S, Barlan I, Yilmaz M, et al. Clinical, functional, and genetic characterization of chronic granulomatous disease in 89 Turkish patients. J Allergy Clin Immun. (2013) 132:1156-63. doi: 10.1016/j.jaci.2013.05.039

16. Fattahi F, Badalzadeh M, Sedighipour L, Movahedi M, Fazlollahi MR, Mansouri SD, et al. Inheritance pattern and clinical aspects of 93 Iranian patients with chronic granulomatous disease. J Clin Immunol. (2011) 31:792801. doi: 10.1007/s10875-011-9567-x

17. Bustamante J, Aksu G, Vogt G, de Beaucoudrey L, Genel F, Chapgier A, et al. BCG-osis and tuberculosis in a child with chronic granulomatous disease. $J$ Allergy Clin Immun. (2007) 120:32-8. doi: 10.1016/j.jaci.2007.04.034

18. Lotte A, Wasz-Höckert O, Poisson N, Dumitrescu N, Verron M, Couvet E. BCG complications. Estimates of the risks among vaccinated subjects and statistical analysis of their main characteristics. Adv Tuberculosis Res. (1983) 21:107-93.

19. Winkelstein JA, Marino MC, Johnston RB Jr, Boyle J, Curnutte J, Gallin JI, et al. Chronic granulomatous disease: report on a national registry of 368 patients. Medicine (2000) 79:155-69. doi: 10.1097/00005792-200005000-00003

20. Yu Y, Zhu W, Wang X. Flow cytometry assay of function of neutrophil in adult and children. Fudan Uni J Med Sci. (2005) 1:101-4. doi: 10.3969/j.issn.1672-8467.2005.01.028

21. Parsons LM, Brosch R, Cole ST, Somoskövi Á, Loder A, Bretzel G, et al. Rapid and simple approach for identification of Mycobacterium tuberculosis complex isolates by PCR-based genomic deletion analysis. J Clin Microbiol. (2002) 40:2339-45. doi: 10.1128/jcm.40.7.2339-2345.2002

22. Bolscher BG, De Boer M, De Klein A, Weening RS, Roos D. Point mutations in the beta-subunit of cytochrome b558 leading to X-linked chronic granulomatous disease. Blood (1991) 77:2482-7.
23. Heyworth PG, Curnutte JT, Rae J, Noack D, Roos D, van Koppen E, et al. Hematologically Important Mutations: X-Linked Chronic Granulomatous Disease (Second Update). Blood Cells Mol Dis. (2001) 27:16-26. doi: 10.1006/bcmd.2000.0347

24. Sun J, Wang Y, Liu D, Yu Y, Wang J, Ying W, et al. Prenatal diagnosis of $\mathrm{X}$-linked chronic granulomatous disease by percutaneous umbilical blood sampling. Scand J Immunol. (2012) 76:512-8. doi: 10.1111/j.1365-3083.2012.02772.x

25. Leusen JH, De Boer M, Bolscher BG, Hilarius PM, Weening RS, Ochs HD, et al. A point mutation in gp91-phox of cytochrome b558 of the human NADPH oxidase leading to defective translocation of the cytosolic proteins p47-phox and p67-phox. J Clin Invest. (1994) 93:2120. doi: 10.1172/JCI117207

26. Roos D, Kuhns DB, Maddalena A, Roesler J, Lopez JA, Ariga T, et al. Hematologically important mutations: X-linked chronic granulomatous disease (third update). Blood Cells Mol Dis. (2010) 45:246-65. doi: 10.1016/j.bcmd.2010.07.012

27. Van den Berg JM, Van Koppen E, Åhlin A, Belohradsky BH, Bernatowska E, Corbeel L, et al. Chronic granulomatous disease: the European experience. PLoS ONE (2009) 4:e5234. doi: 10.1371/journal.pone.0005234

28. Cole T, Pearce MS, Cant AJ, Cale CM, Goldblatt D, Gennery AR. Clinical outcome in children with chronic granulomatous disease managed conservatively or with hematopoietic stem cell transplantation. J Allergy Clin Immun. (2013) 132:1150-5. doi: 10.1016/j.jaci.2013.05.031

29. Güngör T, Teira P, Slatter M, Stussi G, Stepensky P, Moshous D, et al. Reduced-intensity conditioning and HLA-matched haemopoietic stem-cell transplantation in patients with chronic granulomatous disease: a prospective multicentre study. Lancet (2014) 383:436-48. doi: 10.1016/S0140-6736(13)62069-3

30. Casanova J, Jouanguy E, Lamhamedi S, Blanche S, Fischer A. Immunological conditions of children with BCG disseminated infection. Lancet (1995) 346:581. doi: 10.1016/S0140-6736(95)91421-8

31. Wolach B, Gavrieli R, de Boer M, van Leeuwen K, Berger Achituv S, Stauber $\mathrm{T}$, et al. Chronic granulomatous disease: clinical, functional, molecular, and genetic studies. the Israeli experience with 84 patients. Am J Hematol. (2017) 92:28-36. doi: 10.1002/ajh.24573

32. Kuhns DB, Alvord WG, Heller T, Feld JJ, Pike KM, Marciano BE, et al. Residual NADPH oxidase and survival in chronic granulomatous disease. $N$ Engl J Med. (2010) 363:2600-10. doi: 10.1056/NEJMoa1007097

33. Bustamante J, Arias AA, Vogt G, Picard C, Galicia LB, Prando C, et al. Germline $C Y B B$ mutations that selectively affect macrophages in kindreds with X-linked predisposition to tuberculous mycobacterial disease. Nat Immunol. (2011) 12:213-21. doi: 10.1038/ni.1992

34. Gallin JI, Malech HL, Curnutte W, Quie PG, Jaffe HS, Ezkowitz R. A controlled trial of interferon gamma to prevent infection in chronic granulomatous disease. N Engl J Med. (1991) 324:509-16. doi: 10.1056/NEJM199102213240801

35. Weening RS, Leitz GJ, Seger RA. Recombinant human interferon-gamma in patients with chronic granulomatous disease-European follow up study. Eur J Pediatr. (1995) 154:295-8.

36. Marciano BE, Wesley R, Ellen S, Anderson VL, Barnhart LA, Darnell D, et al. Long-term interferon- $\gamma$ therapy for patients with chronic granulomatous disease. Clin Infect Dis. (2004) 39:692-9. doi: 10.1086/422993

37. Martire B, Rondelli R, Soresina A, Pignata C, Broccoletti T, Finocchi A, et al. Clinical features, long-term follow-up and outcome of a large cohort of patients with chronic granulomatous disease: an Italian multicenter study. Clin Immunol. (2008) 126:155-64. doi: 10.1016/j.clim.2007.09.008

Conflict of Interest Statement: The authors declare that the research was conducted in the absence of any commercial or financial relationships that could be construed as a potential conflict of interest.

Copyright (c) 2019 Li, Zhou, Ling, Jiang, Ai, Wu, Chen, Chen, Qian, Liu, Xi, Xia, Fan, Lu and Zhang. This is an open-access article distributed under the terms of the Creative Commons Attribution License (CC BY). The use, distribution or reproduction in other forums is permitted, provided the original author(s) and the copyright owner(s) are credited and that the original publication in this journal is cited, in accordance with accepted academic practice. No use, distribution or reproduction is permitted which does not comply with these terms. 